\title{
Bioavailability and transfer of elevated Sm concentration to alfalfa in spiked soils
}

\author{
Ruoyu HU, Thierry BEGUIRISTAIN, Alexis De JUNET, Corinne LEYVAL* \\ Université de Lorraine, CNRS, LIEC, F-54000 Nancy, France \\ * Corresponding author: corinne.leyval@univ-lorraine.fr, tel. 33(0)372745204
}

\begin{abstract}
Rare earth elements (REEs) have been widely used in recent decades and their exploitation has led to industrial REE emission and to contaminated soils especially in former mining areas. This raised people's concerns on the accumulation and toxicity of REEs in soils and plants, and consequences on plant health. Although many studies dealt with REE in soils and plants, there is still a need to precise their toxicity, bioavailability and transfer to plants in contaminated sites in order to restore such ecosystems. We studied the bioavailability and transfer of a REE to Medicago sativa grown on two contaminated soils differing in their chemical characteristics. A pot experiment was set up in a growth chamber where two natural soils were spiked or not with samarium (Sm) as a model REE. Two chemical extractants were tested to estimate the bioavailability of Sm in the soil, its decrease with time and its transfer to the plants. Results showed that DTPA extractable Sm was well correlated with Sm uptake in alfalfa shoots. The experiment pointed out a significant ageing effect since DTPA extractable Sm significantly decreased within two weeks in the soils and was significantly lower in the less acidic soil than in the other. The uptake of Sm from soil to alfalfa shoots depended on the soil $\mathrm{pH}$ and on the spiking concentration. The soil to plant transfer factor was low $(<0.08)$ but a $30 \%$ reduction of alfalfa biomass was observed when the soils were spiked with 100 to $200 \mathrm{mg} \mathrm{kg}^{-1}$ of Sm.
\end{abstract}

\section{Keywords:}

Rare earth element, Transfer, Soil, Bioavailability, Plant, Ageing

\section{Introduction}

Rare earth elements (REEs) are a group of elements in the periodic table consisting of 15 lanthanide group elements from lanthanum (La) to lutetium (Lu), along with the pseudo lanthanide (Tyler 2004). According mainly to the geochemical behaviour of the REEs, they were divided into light (LREEs; La to Sm) and heavy REEs (HREEs; europium to Lu) (Brioschi et al. 2013). Because of their magnetic, fluorescent and catalytic properties, REEs, especially LREEs are nowadays widely used in many industries especially high-technology industries like electronics and medicine (Loell et al. 2011a; Pagano 2016). In natural soils, REE concentrations range from 40 to $700 \mathrm{mg} \cdot \mathrm{kg}^{-1}$ all over the world and are not considered as toxic for the environment. However, the higher demand and mining of REEs in the past decades have led to a notable increase in REEs in the environment (MacMillan et al. 2019) and high soil REE concentrations in former mining areas (Chao et al. 2016; Khan et al. 2017). For example, REE concentration in soil of Bayan Obo rare earth mining area in China is above $2.7 \times 10^{4} \mathrm{mg} \cdot \mathrm{kg}^{-1}$ due to the mining activity (Liang et al. 2014). Landfills with improperly discarded materials containing REEs might also be a source of contamination.

REE concentrations in plants are very low in natural soils (Tyler 2004), but their phytotoxicity may be a concern in contaminated areas (Carpenter et al. 2015). REEs are not considered as essential elements for plants, but positive effects of REEs at low concentrations were reported on plant growth (Diatloff et al. 1995a; Xu et al. 
2002; Hong et al. 2003; Xiangsheng et al. 2006; Cheng et al. 2015). In China, REEs have even been used to promote plant growth and have been widely applied in agriculture since the 1990s. However, when a high dose of REE fertiliser has been applied, plant growth was limited and even a toxic effect was found (Hong et al. 2003). Diatloff et al. (1995a, b) studied the toxicity of lanthanum (La) and cerium (Ce) on corn and mungbean seedlings in nutrient solutions and showed a strong inhibition of mungbean root elongation and plant growth with Ce (even at $0.2 \mu \mathrm{M}$ ). Thomas et al. (2014) studied the phytotoxicity of La, Ce and Y (yttrium) on germination and growth of native plants and crops in two artificial soils with different $\mathrm{pH}$. However, there is little information on the phytotoxicity of REEs in contaminated soils. The excessive amounts of REEs are not only harmful to plants but are also able to be taken up by plants and enter the food chain, resulting in their accumulation in organisms and finally in human beings (Loell et al. 2011a; Turra et al. 2013). Therefore, studies regarding the effects of REEs in contaminated soils on plants, and their transfer from soil to plants should be carried out (Gonzalez et al. 2014). The LREE uptake by plants involves calcium $\left(\mathrm{Ca}^{2+}\right.$ ion) channels and HREE uptake uses aluminium ( $\mathrm{Al}^{3+}$ ion) channels (Gonzalez et al. 2014; Yuan et al. 2017). The analysis of REEs in different plants on mining and control areas was performed for health risk assessment and showed an enrichment of LREEs in the former (Zhuang et al. 2017) or to identify potential hyperaccumulating plants (Khan et al. 2017).

The bioavailability of REEs has been discussed in many studies but many of them considered natural soils where their concentrations are low, or agricultural soils with fertilizer inputs. The mobility of REEs in soils is affected by REE sources and forms, soil particle size, pH and organic matter content (Tyler 2004; Babula et al. 2008; MacMillan et al. 2019). The bioavailability of REEs and transfer to plants in soils contaminated due to industrial or mining activities has been less considered. Different methods or development of methods have been studied to estimate/predict the uptake of metals in different plants. Among these methods, simple extractants have not been widely investigated for REEs. Using sequential chemical extractions, Cao et al. (2000b) showed that bioavailability of REEs differed with the REEs. Li et al. (2001) compared different extractants and found that $0.1 \mathrm{M} \mathrm{HCl}$ extractable fraction of REEs was well correlated with their concentration in wheat roots and shoots in cultivated soils in China. Li et al. (2018) used $\mathrm{CaCl}_{2}$ to correlate lanthanide toxicity to soil invertebrates with bioavailable fraction in soil. None of these studies considered the ageing of REEs in soil and the consequence on their bioavailability.

This work aimed to study the bioavailability and transfer of a REE to a crop plant Medicago sativa grown on two contaminated soils differing in their chemical characteristics. A pot experiment was set up in a growth chamber where two natural soils were spiked or not with elevated concentrations of Samarium (Sm) as a model REE. The bioavailability of Sm was estimated using two chemical extractants in the spiked and control soils just after spiking, after two weeks of ageing and at plant harvest. Sm phytoavailability was also estimated by plant accumulation at harvest. Plant growth, $\mathrm{P}$ and Ca plant uptake were also estimated.

\section{Material and methods}

\subsection{Experiment design}

The soils used for the experiments were collected from the surface horizon $(5-25 \mathrm{~cm})$ of two sampling sites in north-eastern France: Maron (48³8'45.75"N, 64'48.44"E) and Bouzule (4844'7.95"N, 6¹9'9.64"E). They both belong to Luvisol with different $\mathrm{pH}$ values. The physicochemical parameters of the two sampled soils are shown in Table 1. Soil samples were air-dried, ground, sieved to $2 \mathrm{~mm}$, homogenised and stored in a dry and 
dark room ready to be used in the experiments. The Bouzule soil was partially amended with pre-sieved $(2 \mathrm{~mm})$, washed and dried sand $(30 \mathrm{w} / 70 \mathrm{w})$ to avoid compaction and allow seedling growth. A ten times concentrated solution of $\mathrm{SmCl}_{3} \cdot 6 \mathrm{H}_{2} \mathrm{O}$ in deionized water was added to $1 / 10$ of both soils. The concentrated spiked soils were dried at $50{ }^{\circ} \mathrm{C}$, homogenised, and added to the rest of the unspiked soils and homogenised to obtain 100 and 200 $\mathrm{mg} \cdot \mathrm{kg}^{-1} \mathrm{Sm} .1 \mathrm{~kg}$ of soils were placed in $1 \mathrm{~kg}$ pots with eight replicates and three Sm conditions $(0,100,200$ $\mathrm{mg} \cdot \mathrm{kg}^{-1}$ ) according to LREE concentrations in abandoned mining sites (Chao et al. 2016). Deionized water was added to reach $70 \%$ of water holding capacity (WHC) and pots were placed in a dark room at $4^{\circ} \mathrm{C}$ (T0) for 2 weeks for the ageing of the Sm contamination.

After soil ageing, 4-5-day-old alfalfa (Medicago sativa) seedlings germinated on sterilised vermiculite were transplanted to the pots (T1) with 15 plants in each pot. Pots with plants were transferred to a growth chamber with $16 \mathrm{~h}$ photoperiod, $22^{\circ} \mathrm{C} / 18^{\circ} \mathrm{C}$ day/night, $250 \mu$ mol photons $\mathrm{m}^{-2} \mathrm{~s}^{-1}, 80 \%$ relative humidity for 6 weeks. During the 6-week growing period, the pots were watered twice a week and a nutrient solution (Redon et al. 2009) was added once per week to maintain $70 \%$ WHC.

\subsection{Sampling and analysis}

Soil samples were collected at $\mathrm{T} 0$ and $\mathrm{T} 1 \mathrm{in}$ centrifuge tubes and dried at $80{ }^{\circ} \mathrm{C}$ for $72 \mathrm{~h}$. Alfalfa plants and soil samples were harvested (T2) 28 days (Maron) or 42 days (Bouzule) after transplantation. Pots with Maron soil were harvested earlier due to the poor growth of plants on this soil. Shoots and roots were harvested, gently rinsed with deionized water then dried at $60{ }^{\circ} \mathrm{C}$ for $72 \mathrm{~h}$, and the dry weight of shoots and roots of each pot was recorded. Soil samples were collected at $\mathrm{T} 2$ in centrifuge tubes and dried at $80{ }^{\circ} \mathrm{C}$ for $72 \mathrm{~h}$. All soil and shoot samples were ground in a mortar with a pestle before the analysis.

To analyse the total concentration of Sm in soil, $200 \mathrm{mg}$ of ground soil sample was transferred into an acid-cleaned Teflon tube designed for CEM Mars 5 Digestion Microwave System ${ }^{\circledR}$ and $10 \mathrm{~mL}$ of Aqua regia (nitric acid: hydrochloric acid =1:3 v/v) was added. Digestion was processed under the adapted programme (15 min digestion at $25^{\circ} \mathrm{C}$ and 10 min digestion at $170^{\circ} \mathrm{C}$ ). After the digestion and cooling down procedure, the digested samples were filtered (DigiFILTER, SCP Science ${ }^{\circledR}$ 010-500-070), and the filtered solutions were transferred into $15 \mathrm{~mL}$ centrifuge tubes, adjusted to $10 \mathrm{~mL}$ with ultra-pure deionized water $18 \mathrm{M} \mathrm{W}$ and preserved at $4{ }^{\circ} \mathrm{C}$ till the analysis.

The bioavailable concentrations of Sm in soils were extracted by two different extractants. The DTPA extracting solution consists of diethylenetriaminepentaacetic acid (DTPA) $(0.005 \mathrm{M}), \mathrm{CaCl}_{2}(0.01 \mathrm{M})$ and triethanolamine (0.1M) (Carter and Gregorich 2007; Kim et al. 2015). One gram of ground soil sample was transferred into a $15 \mathrm{~mL}$ centrifuge tube, with $10 \mathrm{~mL}$ of DTPA solution and homogenised on a rotary shaker with $99 \mathrm{rpm}$ for 2 hours. Samples were centrifuged at $3227 \mathrm{~g}$ for $15 \mathrm{~min}\left(20^{\circ} \mathrm{C}\right)$ and the supernatant was filtered in $15 \mathrm{~mL}$ centrifuge tubes, adjusted to $10 \mathrm{~mL}$ with ultra-pure deionized water $18 \mathrm{M} \mathrm{W}$ and preserved at $4{ }^{\circ} \mathrm{C}$ till the analysis. The second extractant is $\mathrm{CaCl}_{2}$. One gram of ground sample was transferred into a $15 \mathrm{~mL}$ centrifuge tube with $10 \mathrm{~mL}$ of $0.01 \mathrm{M} \mathrm{CaCl}_{2}$ solution with the same homogenization and centrifugation method as above. The supernatant was filtered in $15 \mathrm{~mL}$ centrifuge tubes, adjusted to $10 \mathrm{~mL}$ with ultra-pure deionized water $18 \mathrm{M}$ W and preserved at $4{ }^{\circ} \mathrm{C}$ till the analysis. 
Dried shoot samples were digested in nitric acid $\left(\mathrm{HNO}_{3}\right)$ and hydrogen peroxide $\left(\mathrm{H}_{2} \mathrm{O}_{2}\right)$ solution. Six $\mathrm{mL}$ of $69 \% \mathrm{HNO}_{3}(\mathrm{CAS}: 7697-37-2)$ and $3 \mathrm{~mL}$ of $30 \% \mathrm{H}_{2} \mathrm{O}_{2}\left(\mathrm{w} / \mathrm{w} \mathrm{H} \mathrm{H}_{2} \mathrm{O}\right)$ (CAS: 7722-84-1) were added into DigiTUBEs containing $200 \mathrm{mg}$ of ground shoot sample at $20{ }^{\circ} \mathrm{C}$ for a night. Then the DigiTUBEs with the sample solution was placed on DigiPREP MS 48 \& TS (SCP Science ${ }^{\circledR} 010-500-205$ \& 010-500-275) hot plate system covered with DigiPROBE Watch Glass (SCP Science ${ }^{\circledR}$ 010-500-081) processing the digestion programme adapted to plant tissue with 5 min solubilization at $45{ }^{\circ} \mathrm{C}, 10 \mathrm{~min}$ pre-digestion at $65{ }^{\circ} \mathrm{C}$ and $60 \mathrm{~min}$ digestion at $95{ }^{\circ} \mathrm{C}$. After cooling down, the solution was filtered as previously described and kept at $4{ }^{\circ} \mathrm{C}$ until the analysis.

The total and the bioavailable Sm concentrations in soil samples and the concentration of Sm in alfalfa shoots were analysed using coupled plasma-optical emission spectroscopy (ICP-OES) analytical technique using a Varian Inc. ${ }^{\circledR}$ (Part A) - 720/730-ES ICP-OES. Calcium (Ca), sodium (Na), potassium (K) and magnesium (Mg) concentrations in alfalfa shoots were also analysed using the same technique and are presented as supplementary data (Online Resource 1). All the analysis used NCS Certified Reference Material NCS DC 73030 soil (Sm recovery rate $=85.1 \%$ ) and Labmix 24 oriental basma tabacco leaves (track elements) - IC-INCT-OBTL-5 (Sm recovery rate $=70 \%$ ) as references. The soil-plant transfer factor (SPTF) (Papastefanou et al. 1999; Cao et al. 2000a; Chyi 2003; Šmuc et al. 2012) was calculated as the ratio between Sm concentration in alfalfa shoots and the total concentration of Sm in soils.

Statistical analysis was performed with RStudio software (Version 1.1.463 - (C) 2009-2018 RStudio, Inc.). One-way and two-way analysis of variance (ANOVA 1 and 2) and the Tukey honestly-significantdifference (HSD) post-hoc test were performed for the significance of the data with a $95 \%$ significant level (pvalue $\leq 0.05$ ).

\section{Results}

\subsection{Total and extractable $\mathrm{Sm}$ in both soils}

Sm concentration in unspiked Maron and Bouzule soils was $14.83 \pm 0.37 \mathrm{mg} \cdot \mathrm{kg}^{-1}$ and $4.99 \pm 0.46$ $\mathrm{mg} \cdot \mathrm{kg}^{-1}$, respectively. After spiking with 100 and $200 \mathrm{mg} \cdot \mathrm{kg}^{-1} \mathrm{Sm}$, the concentrations were $82.76 \pm 12.25 \mathrm{mg} \cdot \mathrm{kg}^{-}$ ${ }^{1}$ and $169.48 \pm 47.11 \mathrm{mg} \cdot \mathrm{kg}^{-1}$ for Maron soil, and $86.44 \pm 32.62 \mathrm{mg} \cdot \mathrm{kg}^{-1}$ and $151.49 \pm 63.09 \mathrm{mg} \cdot \mathrm{kg}^{-1}$ for Bouzule soil, respectively.

Both $\mathrm{CaCl}_{2}$ and DTPA extractants were used for Maron and Bouzule soils at 3 sampling dates: at spiking (T0), after 2 ageing weeks (T1) and at plant harvest (T2), and in unspiked soils. For Maron soil $\mathrm{CaCl}_{2}$ extractable Sm was below the detection limit $\left(0.1 \mathrm{mg} \cdot \mathrm{kg}^{-1}\right)$ in unspiked soil. In spiked soils, $\mathrm{CaCl}_{2}$ extractable Sm was $0.2 \pm 0.02 \mathrm{mg} \cdot \mathrm{kg}^{-1}$ at T0, $0.1 \pm 0.01 \mathrm{mg} \cdot \mathrm{kg}^{-1}$ at T2 in $100 \mathrm{mg} \cdot \mathrm{kg}^{-1}$ spiked soil, and $0.39 \pm 0.03 \mathrm{mg} \cdot \mathrm{kg}^{-1}$ at $\mathrm{T} 0$ and $0.18 \pm 0.02 \mathrm{mg} \cdot \mathrm{kg}^{-1}$ at $\mathrm{T} 2$ in $200 \mathrm{mg} \cdot \mathrm{kg}^{-1}$ spiked soil. For Bouzule soil, $\mathrm{CaCl}_{2}$ extractable $\mathrm{Sm}$ was below the detection limit in all samples.

The DTPA extractable Sm in unspiked Maron and Bouzule soils was also low: $4.16 \pm 0.58 \mathrm{mg} \cdot \mathrm{kg}^{-1}$ at $\mathrm{T} 0,4.13 \pm 0.35 \mathrm{mg} \cdot \mathrm{kg}^{-1}$ at $\mathrm{T} 1$ and $3.27 \pm 0.45 \mathrm{mg} \cdot \mathrm{kg}^{-1}$ at $\mathrm{T} 2$ in Maron soil, without significant difference between the 3 sampling dates. Much lower DTPA extractable Sm was found in Bouzule soil with $0.36 \pm 0.05$ 
$\mathrm{mg} \cdot \mathrm{kg}^{-1}$ at $\mathrm{T} 0,0.30 \pm 0.03 \mathrm{mg} \cdot \mathrm{kg}^{-1}$ at $\mathrm{T} 1$ and $0.20 \pm 0.005 \mathrm{mg} \cdot \mathrm{kg}^{-1}$ at $\mathrm{T} 2$, with a significant difference between $\mathrm{T} 0$ and $\mathrm{T} 2$.

The DTPA extractable concentration of Sm in the spiked soils decreased as a function of time (Figure 1). It decreased by $16 \%$ and $11 \%$ respectively in 100 and $200 \mathrm{mg} \cdot \mathrm{kg}^{-1}$ spiked Maron soil during the 2-week ageing period from T0 to T1. For Bouzule soil, there was a significant $24 \%$ and $29 \%$ decrease of DTPA extractable $\mathrm{Sm}$ in 100 and $200 \mathrm{mg} \cdot \mathrm{kg}^{-1}$ spiked soil respectively during the 2-week ageing (T0 to T1). A significant decrease was also observed between T1 and T2, during the 4 weeks' alfalfa growing time, with $24 \%$ and $26 \%$ decrease respectively in 100 and $200 \mathrm{mg} \cdot \mathrm{kg}^{-1}$ spiked Maron soil. During the 6 weeks' alfalfa growing time (between T1 and T2), the available Sm concentration in Bouzule spiked soil also significantly decreased with a $48 \%$ and $40 \%$ decrease at 100 and $200 \mathrm{mg} \cdot \mathrm{kg}^{-1} \mathrm{Sm}$ spiked concentration.

\subsection{Alfalfa growth in Sm spiked and unspiked soils}

In Maron soil, the shoot biomass showed a significant decrease in the $200 \mathrm{mg} \mathrm{kg}^{-1} \mathrm{Sm}$ spiked soil compared to the unspiked control but the root biomass showed no significant difference between control and spiked soils. Shoot and root biomass in Bouzule soil was significantly lower in Sm spiked than in the unspiked soil (Figure 2). It was significant already with $100 \mathrm{mg} \cdot \mathrm{kg}^{-1} \mathrm{Sm}$ spiked concentration (p-value $\leq 0.05$ ) and no further decrease was observed at $200 \mathrm{mg} \mathrm{kg}^{-1}$. For Maron soil, the shoot biomass showed a significant decrease in the $200 \mathrm{mg} \mathrm{kg}^{-1} \mathrm{Sm}$ spiked soil compared to the unspiked control but the root biomass showed no significant difference between control and spiked soils.

\subsection{Sm transfer to plants}

The concentration of Sm in alfalfa shoots was significantly higher in the spiked soils than in the controls and was twice higher with 200 than with $100 \mathrm{mg} \mathrm{kg}^{-1} \mathrm{Sm}$ spiked soils (p-value $=0.05$ ) (Figure 3). The soil-plant transfer factor (SPTF) was around 0.05-0.08 in Maron soil, and it was not significantly different between spiked and unspiked soils. However, in Bouzule soil, the SPTF was around 0.02 to 0.035 and was significantly lower in spiked than in unspiked soil (Figure 3). The Sm uptake by plants as a function of DTPAextractable concentration of Sm in soil was also calculated (Figure 4) and showed a positive linear correlation $\left(\mathrm{R}^{2}=0.9334\right.$, linear regression model).

We analysed $\mathrm{P}$ and $\mathrm{Ca}$ concentrations in plants. There were no significant differences in $\mathrm{P}$ and $\mathrm{Ca}$ concentrations in alfalfa shoots between unspiked and spiked soils (data not shown). P and Ca content in shoots was also not significantly different between spiked and unspiked Maron soil. However, in Bouzule spiked soil, the content of $\mathrm{P}$ and $\mathrm{Ca}$ in shoots was significantly lower than in unspiked soil (Figure 5).

\section{Discussion}

\subsection{Assessment of bioavailability of Sm using different extractants}

Different extractants and extraction methods have been applied to study the bioavailability of REEs in the soil or their phytoavailability and potential uptake by plants. In our study, we performed a single extraction method using two neutral extractants: DTPA and $\mathrm{CaCl}_{2}$. Our results showed that $\mathrm{CaCl}_{2}$ extractant had a low extracting ability, while the phytoavailable Sm in the soil was well predicted by DTPA extraction as the Sm 
plant uptake accounted for $22.9 \%$ of DTPA extractable Sm (with $\mathrm{R}^{2}=0.93$ ). According to Rao et al. (2010), the bioavailability of REEs can be overestimated by strong acid reagents such as $\mathrm{CH}_{3} \mathrm{COOH}$ and $\mathrm{HCl}$. Meanwhile, the complexing extractants such as DTPA and EDTA showed moderate extraction ability and have been applied in different studies. EDTA was used to indicate that $10 \%$ to $16 \%$ of REEs were phytoavailable in natural soils in central Germany (Loell et al. 2011a, b). EDTA showed a stronger extracting ability than DTPA as it can extract both carbonate and organically bound fractions of metals in soils with low carbonate content (Sahuquillo et al. 2003). For Censi et al. (2017), DTPA gave a good indication of the plant-bioavailable fraction of REEs and other trace elements in rural, urban and industrial soils in Sicily. The neutral salt $0.01 \mathrm{M} \mathrm{CaCl}_{2}$ was recommended as a good extractant of phytoavailability (Menzies et al. 2007; Kim et al. 2015). However, in our study, $\mathrm{CaCl}_{2}$ could not be used to represent alfalfa available Sm in both soils due to its weak extraction ability, while DTPA showed a good indication of alfalfa available $\mathrm{Sm}$ in the soil.

\subsection{Bioavailability of high concentration of $\mathrm{Sm}$ in soils and influence of ageing}

In our study, the bioavailable Sm, estimated by DTPA extraction, accounted for $40 \%$ of the total $\mathrm{Sm}$ concentration (extracted by aqua regia) in freshly spiked Maron soil and $25 \%$ in freshly spiked Bouzule soil. Despite the same spiking concentrations in both soils, it was significantly higher in the acidic Maron soil than the more neutral Bouzule soil. In a study of four types of Chinese soils, with both control and spiked (200 $\mathrm{mg} \cdot \mathrm{kg}^{-1}$ REEs) soils, the red earth with lowest $\mathrm{pH}$ had the highest exchangeable REEs (Liang et al. 2005). A higher REE availability in lower $\mathrm{pH}$ soil was also reported in a study comparing total REE contents and the potentially bioavailable fraction using EDTA in three different soils in Germany (Diatloff et al. 1995b). Diatloff et al. (1996) found that the $\mathrm{Ca}\left(\mathrm{NO}_{3}\right)_{2}$ extractable REEs decreased with the soil $\mathrm{pH}$ increase when adding $\mathrm{CaCO}_{3}$ and increased when soil $\mathrm{pH}$ decreased by adding $\mathrm{CaSO}_{4} \cdot 2 \mathrm{H}_{2} \mathrm{O}$. Yufeng et al. (2003) applied artificial acid rainwater to Chinese red soil and showed an increase in the REE concentrations in the soil leaching solution after the acid rainwater application. Our result of higher bioavailable Sm in Maron soil further confirmed $\mathrm{pH}$ as an important parameter influencing the bioavailability of REEs.

Despite soil pH and soil composition, the organic matter in soil with a large amount of negatively charged groups is able to adsorb or chelate cations as REEs and thereby decrease their availability and transfer (Tyler 2004; Loell et al. 2011b; Fiket et al. 2017). In our study, the bioavailability of Sm is higher in Maron soil even though the organic matter was higher than in Bouzule soil, indicating that the $\mathrm{pH}$ had a major influence on REE bioavailability. $\mathrm{Ca}^{2+}$ was reported to have an influence on the bioavailability of LREE to plant, as LREE are reported to use the same ion channels as $\mathrm{Ca}^{2+}$ when entering plant root (Yuan et al. 2017). In our study, there was no indication that $\mathrm{Ca}$ concentration influenced the bioavailability of the LREE Sm, but calcium concentration in both soils was similar.

Other than the above-mentioned factors, the ageing significantly affected the bioavailability of Sm in the spiked soils. In our study, the bioavailable fraction of Sm significantly decreased within the two weeks of ageing. Cao et al. (2000b) studied the bioavailability of REEs in natural soils using the same model plant alfalfa (Medicago sativa) and sequential extractions. They showed that exchangeable REE fraction contributed to the bioavailable REEs, which explained the decreased bioavailability of REEs, including Sm, with time as REEs were adsorbed to soil particles. In the unspiked soils, the bioavailable fraction of Sm was much lower than in the spiked soils (26 and $6 \%$ for Maron and Bouzule, respectively), which was also observed for natural and spiked 
soils by Liang et al. (2005). The bioavailable fraction of REEs accounted for only $10.1 \%$ of total REEs and $13.8 \%$ of Sm in natural soil (Loell et al. 2011b). We also observed a further decrease of the bioavailable Sm from T1 to T2 down to $25 \%$ in Maron and $9 \%$ in Bouzule soil which could be due to the ageing effect and the presence of alfalfa plants as well. Therefore, REE toxicity studies with spiked soils (Thomas et al., 2014) should include an ageing period of the soil before to introduce the plants.

\subsection{Impact of high concentration of Sm on plant growth}

Although some studies have mentioned a positive influence of REEs on plant growth at low concentration in soil (Hong et al. 2003; Cheng et al. 2015), other studies reported the inhibition of plant growth and toxic effects of high concentrations REEs to plants (Carpenter et al. 2015). However, most of the studies on the effects of REEs on plant growth were performed in liquid media (Asher and Smith 1995; Diatloff et al. 1995a, b; d'Aquino et al. 2009) on two or three LREEs (yttrium, lanthanum and cerium) and not in soil. Few data are focusing on the effect of single elements (Pagano 2016). In our study, we focused on the effect of a single REE on alfalfa. REE toxicity and transfer to plants may differ with plant species and REEs. This was observed with elevated La, Y and Ce concentrations in artificial spiked soil where lower IC25s values for Ce and some plants were observed (Thomas et al. 2014). However, we showed a strong decrease, around 30\%, of alfalfa shoot biomass when the Sm concentration in soil reached 100 to $200 \mathrm{mg} \cdot \mathrm{kg}^{-1}$. Carpenter et al. (2015) showed that the IC25s of native plants in artificial soils spiked with 6 REEs was between 100 and $300 \mathrm{mg} \cdot \mathrm{kg}^{-1}$ REEs, but the ageing of the contamination was not considered neither in the experiment of Liang et al. (2005) where ryegrass weight was inhibited by spiking REEs on natural soils. Since the spiking was performed with $\mathrm{SmCl}_{3}$, a potential effect of $\mathrm{Cl}$ addition might be considered. Salinity, for example addition of $\mathrm{NaCl}$, can be harmful to alfalfa growth and lead to decreased concentration of shoot K, Ca and P (Li et al. 2010; Ashrafi et al. 2018). However, compared to these experiments, the added $\mathrm{Cl}$ concentration in our study was much lower. Further, the concentration of $\mathrm{Ca}$, and $\mathrm{P}$, and $\mathrm{Na}$ and $\mathrm{K}$ in plants was not significantly different between $\mathrm{SmCl}_{3}$ spiked and non-spiked soil (Online Resource 1), suggesting no side effect of the addition of $\mathrm{Cl}$.

\subsection{Transfer of Sm to plants}

The SPTF of Sm was rather low: 0.05 and about 0.08 in the control and spiked Maron soil, respectively, and 0.035 and about 0.02 in the control and spiked Bouzule soil. The difference between control and spiked soils can be explained by the source and ageing time of Sm. In studies focussing on natural soils, the transfer of REEs to plants, especially to wheat seeds (Liang et al. 2005) or fruits (Cheng et al. 2015) was also low (around 0.03). According to Tyler (2004), the concentrations of REEs in the plant are generally low due to the low SPTF, ranging between 0.04 to 0.09 and even lower in grass (Tyler and Olsson 2001) and vegetables (Bibak et al. 1999). In an experiment using REE-containing coal fly ash amendment He et al. (2019) showed a transfer factor from soil to alfalfa shoots of the light REEs La and Ce, and of the heavy REE Y ranging from 0.01 to 0.10. The transfer factor depended on the element and was higher for Ce than the two other REEs. Our results for Maron soil fit with this range of data and the SPTF is lower in Bouzule soil which was mainly influenced by the availability of Sm in the soil. Moreover, the preferable neutral soil for alfalfa lead to better growth in Bouzule soil and a dilution effect occurred. Other plants reported to be hyperaccumulators, such as Phytolacca Americana that can accumulate up to $623 \mathrm{mg} \cdot \mathrm{kg}^{-1}$ REEs or the Chinese fern Dicranopteris dichotoma, showed 
higher SPTF values, up to 75, depending on the soil properties and REE concentrations (Chen et al. 2016; van der Ent et al. 2018). Our study focused on REE transfer from a contaminated soil to a widespread crop plant with rapid growth, where, although the SPTF value is lower, the plant can be strongly impacted by the presence of REEs.

\section{Conclusions}

Although the SPTF of Sm to alfalfa represented a low percentage, the presence of Sm at high concentration inhibited the growth of alfalfa. In areas with a high natural abundance of REEs, in post-mining sites, or with the increasing risk of uncontrolled landfills, non-adapted plants might then be strongly impacted. $\mathrm{pH}$ was a key parameter of the bioavailability of Sm since higher Sm availability and higher SPTF were found in the acid soil. The bioavailable Sm decreased during the ageing process in the soils, suggesting interactions between Sm and soil constituents. A decrease with time of the bio- and phytoavailability of REE in contaminated soils can be expected and help native or crop plants to cope with the presence of REEs. However, in order to further reduce the bioavailability and the transfer to plants of REEs in contaminated soils, and restore such ecosystems, other soil parameters could be considered such as Ca content and organic matter. Rhizospheric processes, such as root exudation or the contribution of root-associated microorganisms, which are known to affect the mobility and availability of metallic trace elements, should also be investigated for REEs.

\section{Acknowledgements}

This work was supported by the French National Research Agency through the national program "Investissements d'avenir" with the reference ANR-10-LABX-21- RESSOURCES21. The authors would like to give thanks to the technical staff of LIEC especially David BILLET, Christine FRIRY and Hervé MARMIER, and to the Experimental phytotronic platform of Lorraine (PEPLor, Université de Lorraine).

\section{References}

Asher CJ, Smith FW (1995) Rare earth elements and plant growth: II. responses of corn and mungbean to low concentrations of lanthanum in dilute, continuously flowing nutrient solutions. J Plant Nutr 18:1977-1989

Ashrafi E, Razmjoo J, Zahedi M (2018) Effect of salt stress on Growth and Ion accumulation of alfalfa (Medicago sativa L.) cultivars. J Plant Nutr 41:818-831

Babula P, Adam V, Opatrilova R, Zehnalek J, Havel L, Kizek R (2008) Uncommon heavy metals, metalloids and their plant toxicity: A review. Environ Chem Lett 6:189-213

Bibak A, Stümp S, Knudsen L, Gundersen V (1999) Concentrations of 63 elements in cabbage and sprouts in Denmark. Commun Soil Sci Plant Anal 30:2409-2418

Brioschi L, Steinmann M, Lucot E, Pierret MC, Stille P, Prunier J, Badot PM (2013) Transfer of rare earth elements (REE) from natural soil to plant systems: Implications for the environmental availability of anthropogenic REE. Plant Soil 366:143-163

Cao X, Chen Y, Gu Z, Wang X (2000a) Determination of trace rare earth elements in plant and soil samples by inductively coupled plasma-mass spectrometry. Int J Environ Anal Chem 76:295-309

Cao X, Wang X, Zhao G (2000b) Assessment of the bioavailability of rare earth elements in soils by chemical 
fractionation and multiple regression analysis. Chemosphere 40:23-28

Carpenter D, Boutin C, Allison JE, Parsons JL, Ellis DM (2015) Uptake and Effects of Six Rare Earth Elements (REEs) on Selected Native and Crop Species Growing in Contaminated Soils. PLoS One 10:e0129936

Carter MR, Gregorich EG (2007) Soil Sampling and Methods of Analysis, Second Edition, 2nd Editio. CRC Press, Boca Raton, USA

Censi P, Cibella F, Falcone EE, Cuttitta G, Saiano F, Inguaggiato C, Latteo V (2017) Rare earths and trace elements contents in leaves: A new indicator of the composition of atmospheric dust. Chemosphere 169:342-350

Chao Y, Liu W, Chen Y, Chen W, Zhao L, Ding Q, Wang S, Tang Y-T, Zhang T, Qiu R-L (2016) Structure, Variation, and Co-occurrence of Soil Microbial Communities in Abandoned Sites of a Rare Earth Elements Mine. Environ Sci Technol 50:11481-11490

Chen Z, Chen Z, Bai L (2016) Rare earth element migration in gullies with different Dicranopteris dichotoma covers in the Huangnikeng gully group, Changting County, Southeast China. Chemosphere 164:443-450

Cheng J, Ding C, Li X, Zhang T, Wang X (2015) Rare earth element transfer from soil to navel orange pulp (Citrus sinensis Osbeck cv. Newhall) and the effects on internal fruit quality. PLoS One 10:1-15

Chyi LL (2003) Trace elements in soils and plants, 4th Editio. CRC Press, Boca Raton, USA

d'Aquino L, de Pinto MC, Nardi L, Morgana M, Tommasi F (2009) Effect of some light rare earth elements on seed germination, seedling growth and antioxidant metabolism in Triticum durum. Chemosphere 75:900905

Diatloff E, Asher CJ, Smith FW (1996) Concentrations of rare earth elements in some Australian soils. Aust J Soil Res 34:735-747

Diatloff E, Smith FW, Asher CJ (1995a) Rare earth elements and plant growth: III. Responses of corn and mungbean to low concentrations of cerium in dilute, continuously flowing nutrient solutions. J Plant Nutr 18:1991-2003

Diatloff E, Smith FW, Asher CJ (1995b) Rare earth elements and plant growth: I. Effects of lanthanum and cerium on root elongation of corn and mungbean. J Plant Nutr 18:1963-1976

Fiket Ž, Medunić G, Furdek Turk M, Ivanić M, Kniewald G (2017) Influence of soil characteristics on rare earth fingerprints in mosses and mushrooms: Example of a pristine temperate rainforest (Slavonia, Croatia). Chemosphere 179:92-100

Gonzalez V, Vignati DAL, Leyval C, Giamberini L (2014) Environmental fate and ecotoxicity of lanthanides: Are they a uniform group beyond chemistry? Environ Int 71:148-157

He H, Fan C, Peng Q, Wu M, Zheng J, Wu G (2019) Bioaccumulation and translocation of rare earth elements in two forage legumes grown in soils treated with coal fly ash. Chem Geol 528:119284

Hong F, Wang L, Liu C (2003) Study of lanthanum on seed germination and growth of rice. Biol Trace Elem Res 94:273-286

Khan AM, Behkami S, Yusoff I, Md Zain S Bin, Bakar NKA, Bakar AFA, Alias Y (2017) Geochemical characteristics of rare earth elements in different types of soil: A chemometric approach. Chemosphere 184:673-678

Kim RY, Yoon JK, Kim TS, Yang JE, Owens G, Kim KR (2015) Bioavailability of heavy metals in soils: definitions and practical implementation-a critical review. Environ Geochem Health 37:1041-1061 
Li F, Shan X, Zhang S (2001) Evaluation of single extractants for assessing plant availability of rare earth elements in soils. Commun Soil Sci Plant Anal 32:2577-2587

Li J, Verweij RA, van Gestel CAM (2018) Lanthanum toxicity to five different species of soil invertebrates in relation to availability in soil. Chemosphere 193:412-420

Li R, Shi F, Fukuda K, Yang Y (2010) Effects of salt and alkali stresses on germination, growth, photosynthesis and ion accumulation in alfalfa (Medicago sativa L.). Soil Sci Plant Nutr 56:725-733

Liang T, Li K, Wang L (2014) State of rare earth elements in different environmental components in mining areas of China. Environ Monit Assess 186:1499-1513

Liang T, Zhang S, Wang L, Kung H Te, Wang Y, Hu A, Ding S (2005) Environmental biogeochemical behaviors of rare earth elements in soil-plant systems. Environ Geochem Health 27:301-311

Loell M, Albrecht C, Felix-Henningsen P (2011a) Rare earth elements and relation between their potential bioavailability and soil properties, Nidda catchment (Central Germany). Plant Soil 349:303-317

Loell M, Reiher W, Felix-Henningsen P (2011b) Contents and bioavailability of rare earth elements in agricultural soils in Hesse (Germany). J Plant Nutr Soil Sci 174:644-654

MacMillan GA, Clayden MG, Chételat J, Richardson MC, Ponton DE, Perron T, Amyot M (2019) Environmental Drivers of Rare Earth Element Bioaccumulation in Freshwater Zooplankton. Environ Sci Technol 53:1650-1660

Menzies NW, Donn MJ, Kopittke PM (2007) Evaluation of extractants for estimation of the phytoavailable trace metals in soils. Environ Pollut 145:121-130

Pagano G (2016) Rare Earth Elements in Human and Environmental Health, 1st edn. Jenny Stanford, Singapore Papastefanou C, Manolopoulou M, Stoulos S, Ioannidou A, Gerasopoulos E (1999) Soil-to-plant transfer of 137Cs, 40K and 7Be. J Environ Radioact 45:59-65

Rao CRM, Sahuquillo A, Lopez-Sanchez JF (2010) Comparison of single and sequential extraction procedures for the study of rare earth elements remobilisation in different types of soils. Ananlytica Chim Acta $662: 128-136$

Redon PO, Béguiristain T, Leyval C (2009) Differential effects of AM fungal isolates on Medicago truncatula growth and metal uptake in a multimetallic $(\mathrm{Cd}, \mathrm{Zn}, \mathrm{Pb})$ contaminated agricultural soil. Mycorrhiza 19:187-195

Sahuquillo A, Rigol A, Rauret G (2003) Overview of the use of leaching/extraction tests for risk assessment of trace metals in contaminated soils and sediments. TrAC Trends Anal Chem 22:152-159

Šmuc NR, Dolenec T, Serafimovski T, Dolenec M, Vrhovnik P (2012) Geochemical characteristics of rare earth elements (REEs) in the paddy soil and rice (Oryza sativa L.) system of Kočani Field, Republic of Macedonia. Geoderma 183-184:1-11

Thomas PJ, Carpenter D, Boutin C, Allison JE (2014) Rare earth elements (REEs): Effects on germination and growth of selected crop and native plant species. Chemosphere 96:57-66

Turra C, De Nadai Fernandes EA, Bacchi MA, Sarriés GA, Júnior FB, Reyes AEL (2013) Rare earth elements in citrus production systems. J Plant Nutr 36:762-771

Tyler G (2004) Rare earth elements in soil and plant systems - A review. Plant Soil 267:191-206

Tyler G, Olsson T (2001) Plant uptake of major and minor mineral elements as influenced by soil acidity and liming. Plant Soil 230:307-321 
van der Ent A, Echevarria G, Baker AJM, Morel JL (2018) Agromining: Farming for Metals. Springer International Publishing, Cham

Xiangsheng L, Jiachen W, Jun Y, Yubin F, Yanping W, He Z (2006) Application of Rare Earth Phosphate Fertilizer in Western Area of China. J Rare Earths 24:423-426

Xu X, Zhu W, Wang Z, Witkamp GJ (2002) Distributions of rare earths and heavy metals in field-grown maize after application of rare earth-containing fertilizer. Sci Total Environ 293:97-105

Yuan M, Guo M-N, Liu W-S, Liu C, van der Ent A, Morel JL, Huot H, Zhao W-Y, Wei X-G, Qiu R-L, et al (2017) The accumulation and fractionation of Rare Earth Elements in hydroponically grown Phytolacca americana L. Plant Soil 421:67-82

Yufeng Z, Zhenghua W, Xiaorong W, Lemei D, Yijun C (2003) Mobility of the Rare Earth Elements with Acid Rainwater Leaching in the Soil Column. Bull Environ Contam Toxicol 67:399-407

Zhuang M, Zhao J, Li S, Liu D, Wang K, Xiao P, Yu L, Jiang Y, Song J, Zhou J, et al (2017) Concentrations and health risk assessment of rare earth elements in vegetables from mining area in Shandong, China.

Chemosphere 168:578-582

Table 1 Physico-chemical characteristics of the soils used in the experiment

\begin{tabular}{lll}
\hline & Maron & Bouzule \\
\hline Soil $\mathrm{pH}$ & 5.34 & 6.68 \\
Sand: silt: clay $(\%)$ & $81: 362: 557$ & $167: 513: 320$ \\
$\mathrm{CaCO}_{3}\left(\mathrm{~g} \cdot \mathrm{kg}^{-1}\right)$ & 0 & 0 \\
Organic carbon $\left(\mathrm{g} \cdot \mathrm{kg}^{-1}\right)$ & 40.1 & 15.8 \\
Total Nitrogen $\left(\mathrm{g} \cdot \mathrm{kg}^{-1}\right)$ & 3.1 & 1.7 \\
Organic matter $\left(\mathrm{g} \cdot \mathrm{kg}^{-1}\right)$ & 69.4 & 27.4 \\
$\mathrm{C} / \mathrm{N}$ & 13.0 & 9.6 \\
$\mathrm{P}\left(\mathrm{mg} \cdot \mathrm{kg}^{-1}\right)$ & 8 & 91 \\
$\mathrm{CEC} \mathrm{cobalthexamine}\left(\mathrm{cmol}^{+} \cdot \mathrm{kg}^{-1}\right)$ & 23.2 & 16.1 \\
$\left.\mathrm{Saturation} \mathrm{rate}^{-1} \%\right)$ & 85 & 100 \\
$\mathrm{Ca}\left(\mathrm{cmol}^{+} \cdot \mathrm{kg}^{-1}\right)$ & 18.1 & 13.1 \\
$\mathrm{Mg}\left(\mathrm{cmol}^{+} \cdot \mathrm{kg}^{-1}\right)$ & 1.07 & 1.79 \\
$\mathrm{Na}\left(\mathrm{cmol}^{+} \cdot \mathrm{kg}^{-1}\right)$ & 0.07 & 0.11 \\
$\mathrm{~K}\left(\mathrm{cmol}^{+} \cdot \mathrm{kg}^{-1}\right)$ & 0.50 & 1.14 \\
$\mathrm{Fe}\left(\mathrm{cmol}^{+} \cdot \mathrm{kg}^{-1}\right)$ & 0.03 & 0.01 \\
$\mathrm{Mn}\left(\mathrm{cmol}^{+} \cdot \mathrm{kg}^{-1}\right)$ & 0.73 & 0.30 \\
$\mathrm{Al}\left(\mathrm{cmol}^{+} \cdot \mathrm{kg}^{-1}\right)$ & 1.45 & 0.05 \\
\hline
\end{tabular}


(a) Maron soil

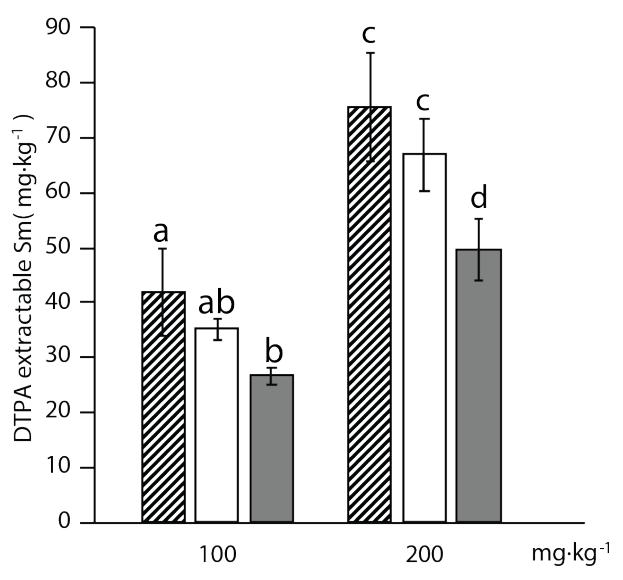

(b) Bouzule soil

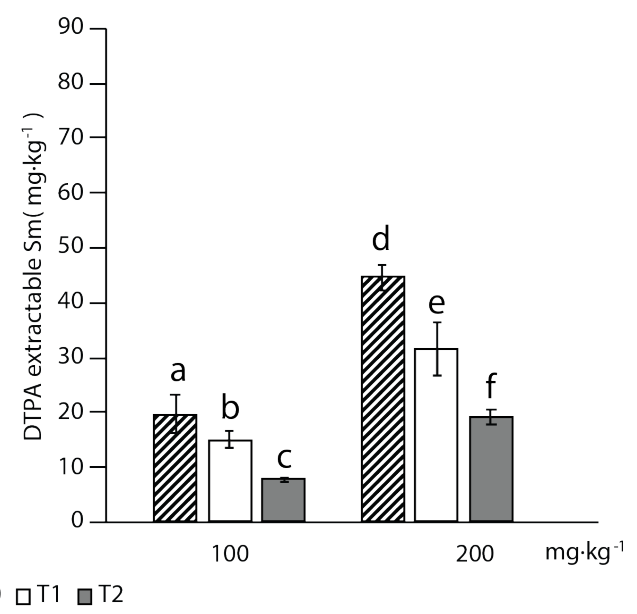

Figure1 DTPA extractable Sm concentration ( $\mathrm{mg} \mathrm{kg}^{-1}$ ) in (a) Maron and (b) Bouzule spiked soils as a function of time ( $\mathrm{T} 0=0, \mathrm{~T} 1=14$ days, $\mathrm{T} 2=42$ days (Maron) and 56 days (Bouzule)) and spiked Sm concentration (100 and $200 \mathrm{mg} \mathrm{kg}^{-1}$ ). Different letters within a soil indicate significant differences (two-way ANOVA, $\mathrm{p}<0.05$ ). 
(a) Maron soil

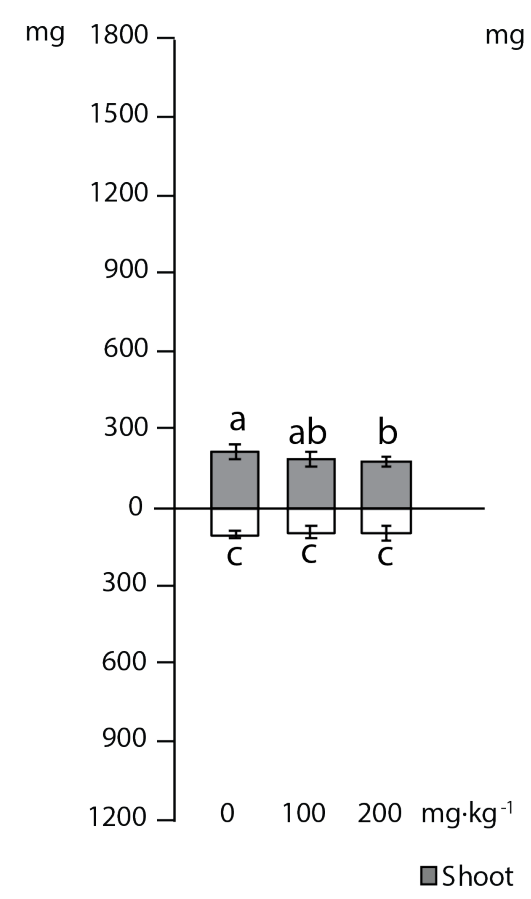

(b) Bouzule soil

mg 1800

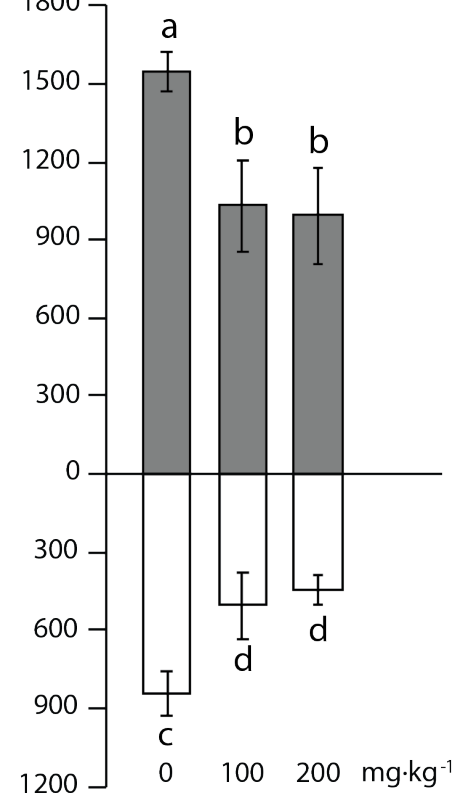

Figure 2 Shoot and root dry weight (mg) of alfalfa plants in (a) Maron and (b) Bouzule soil as a function of spiked Sm concentration $\left(0,100\right.$ and $\left.200 \mathrm{mg} \mathrm{kg}^{-1}\right)$. Mean $\pm \mathrm{SD}(\mathrm{n}=8)$. Different letters within a soil indicate significant differences (two-way ANOVA, $\mathrm{p}<0.05$ ). 


\section{(a) Maron soil}

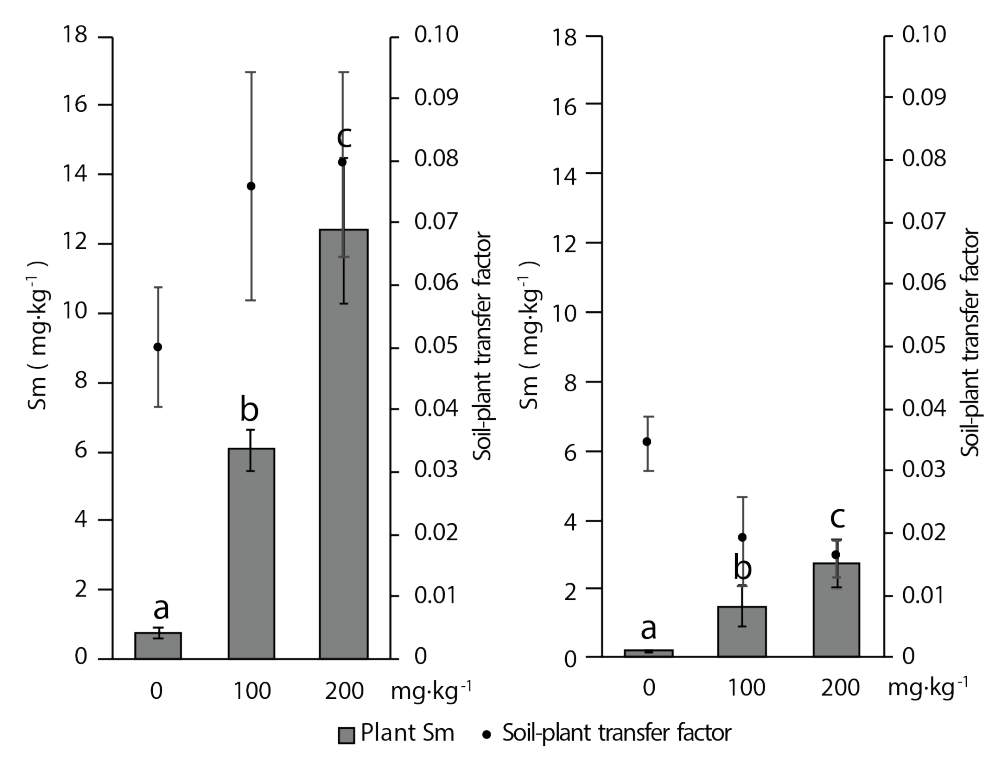

Figure $3 \mathrm{Sm}$ concentration $\left(\mathrm{mg} \mathrm{kg}^{-1}\right)$ in alfalfa shoots growing in (a) Maron and (b) Bouzule soil as a function of Sm spiked concentration $\left(0,100 \mathrm{mg} \mathrm{kg}^{-1}\right.$ and $\left.200 \mathrm{mg} \mathrm{kg}^{-1}\right)$ and soil-plant transfer factor. Mean $\pm \mathrm{SD}(\mathrm{n}=8)$. Different letters within a soil indicate significant differences (two-way ANOVA, $\mathrm{p}<0.05$ ).

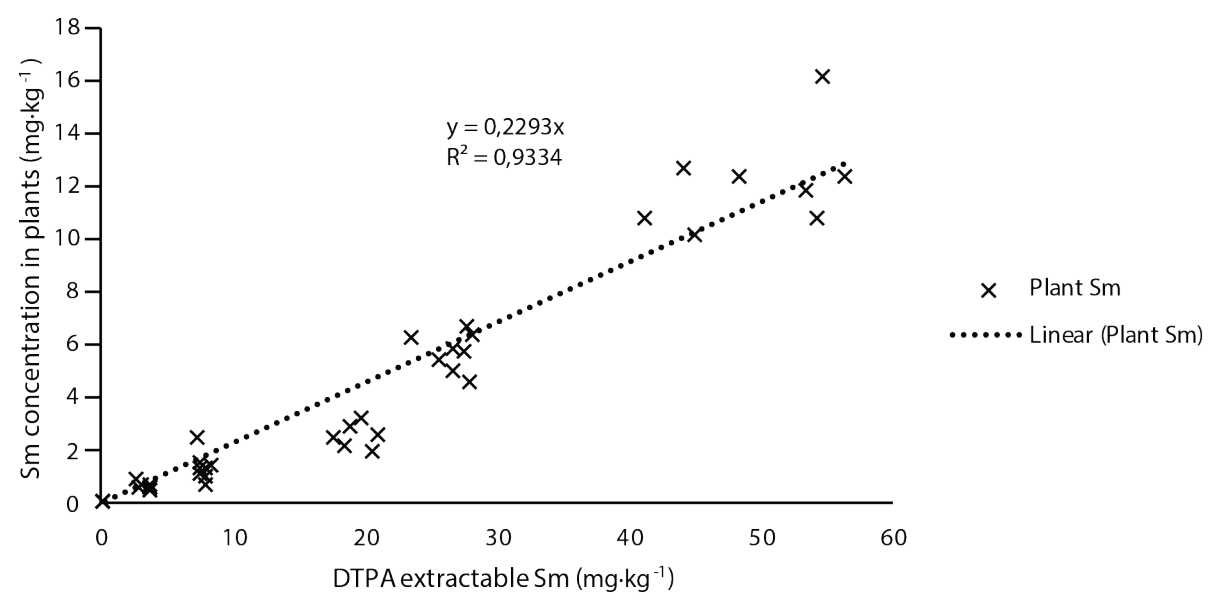

Figure $4 \mathrm{Sm}$ concentration $\left(\mathrm{mg} \mathrm{kg}^{-1}\right)$ in plants as a function of the DTPA extractable $\mathrm{Sm}$ in spiked and unspiked soils. 
Maron soil Bouzule soil

(a) Samarium

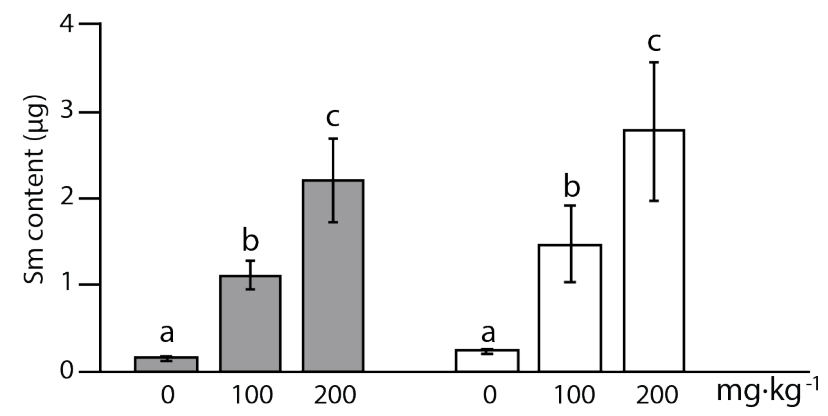

(b) Calcium

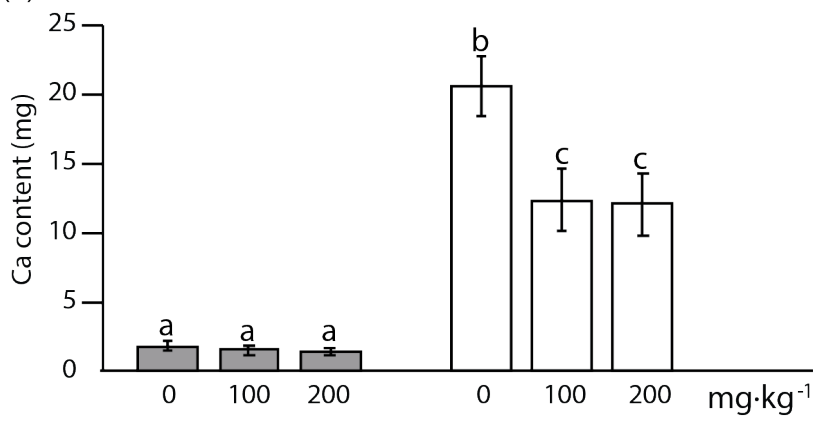

(c) Phosphorus

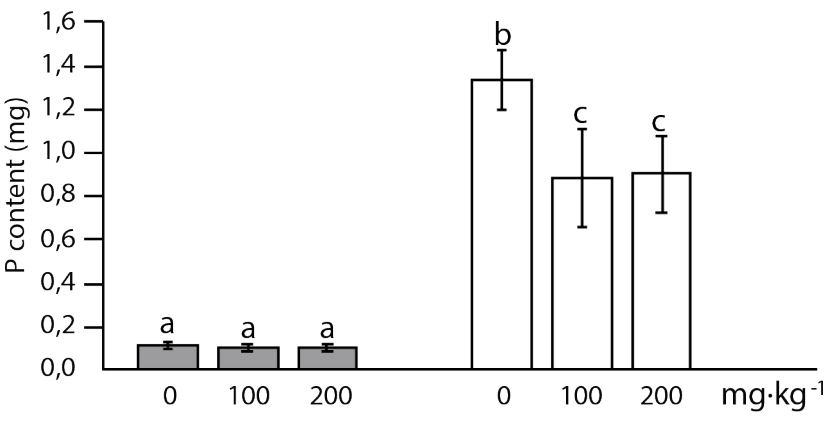

Figure 5 Content of (a) Sm ( $\mu \mathrm{g})$, (b) $\mathrm{Ca}(\mathrm{mg})$ and (c) P (mg) in alfalfa shoots growing in two soils as a function of Sm concentration $(0,100 \mathrm{ppm}$ and $200 \mathrm{ppm})$. Mean $\pm \mathrm{SD}(\mathrm{n}=8)$. Different letters within a soil indicate significant differences (two-way ANOVA, $\mathrm{p}<0.05$ ). 


\section{Online supplementary material}
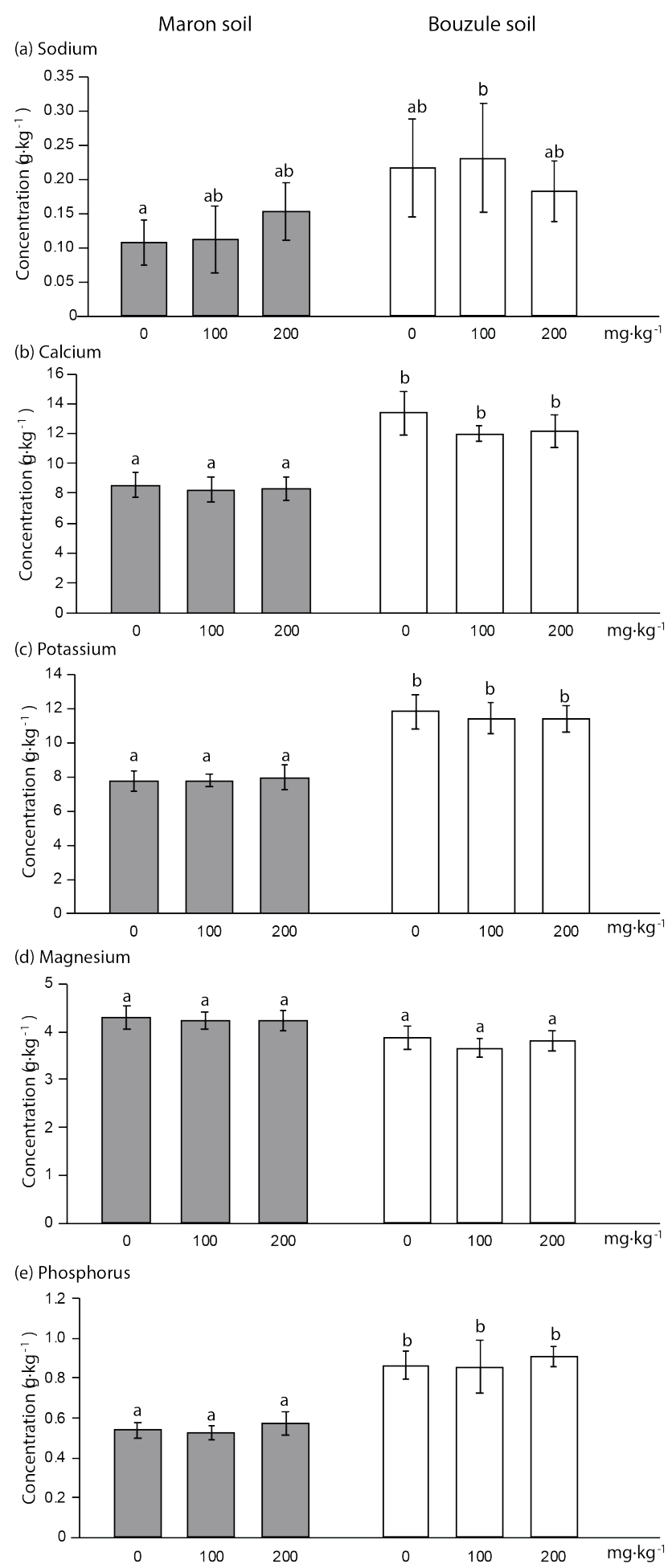

Figure caption: Concentration of (a) $\mathrm{Na}$, (b) $\mathrm{Ca}$, (c) $\mathrm{K}$, (d) $\mathrm{Mg}$ and (e) $\mathrm{P}\left(\mathrm{mg} \mathrm{kg}^{-1}\right.$ ) in alfalfa shoots growing in two soils as a function of Sm concentration $(0,100 \mathrm{ppm}$ and $200 \mathrm{ppm})$. Mean $\pm \mathrm{SD}(\mathrm{n}=8)$. Different letters within a soil indicate significant differences (two-way ANOVA, $\mathrm{p}<0.05$ ) 